\title{
RESENHA DISSERTAÇÃO
}

\section{Criança, Infância e Escola:}

\section{Uma Análise da Produção Discente no Brasil (1994 a 2004). Ezir Mafra Batista.}

“Não se passa do possível ao real, mas do impossível ao verdadeiro.

O que vai do possível ao real o que se fabrica o que se produz. Mas o que nasce, começa sendo impossível e termina sendo verdadeiro". Jorge Larrosa.

\section{Contexto da pesquisa.}

A dissertação analisada teve como contexto o campo de pesquisa infância e educação. O foco incidiuse especificamente sobre os estudos que tecem as categorias escola e infância, conseqüentemente sobre a criança.

Considerando que grande parte da produção acadêmica nacional na área educacional se origina dos cursos de pós-graduação, o estudo da produção acadêmica permite acompanhar o caminho percorrido na área, ao mesmo tempo em que possibilita identificar pontos de convergência e divergência com relação à realidade do país.

Prática científica que compõem a pesquisa que para Bernadete Gatti (2002), define-se pelo ato pelo qual procuramos obter conhecimento sobre alguma coisa, em educação; pesquisar significa trabalhar com algo relativo a seres humanos ou com eles mesmos, em seu processo de vida.

A relevância de um trabalho nesta perspectiva está em examinar os processos e os produtos da atividade científica. Partindo do pressuposto que o papel da universidade é contribuir na produção de um conhecimento seja por definição rigorosa e, para tal, deve ser explícito. Toma-se assim imprescindível que a mesma realize o seu traço mais distintivo na prática científica, conforme esclarece Canário (1996): "a sua capacidade para, de forma permanente, explicitar o que faz, por que faz, questionando sistematicamente seus modos de fazer".

Das constatações alcançadas, destaca-se que embora fossem discutidos na produção acadêmica, vários aspectos que dizem respeito à escola, esta não era revelada em sua totalidade e complexidade; havia 
fragmentação da análise sobre o objeto de estudo que é a escola, já que a tendência predominante nas pesquisas era a fixar-se em apenas um de seus aspectos, como por exemplo: o ensino de determinada disciplina ou currículo, e não buscar compreender a trama das relações em que esse aspecto estava envolvido. Verificaram-se, também, diferentes modos de conceituar a escola, implicando em distintos graus de pertinência dos sujeitos que a constitui, especialmente a criança.

Na amostra, conforme a autora, ficou marcada a preponderância da busca pelos aspectos cognitivos para identificar indicativos metodológicos e para se elaborar a melhor forma de organizar o ensino, em detrimento de outros saberes e informações que as crianças e adolescentes têm a declarar. Além disso, permanece a impressão de que no âmbito educacional pouco se conhece sobre o ser social concreto, complexo e dinâmico que é criança, detendo-se na imagem do adulto, em seus problemas e dificuldades.

Ao sublinhar-se o acanhado número de pesquisas que acessam as vozes infantis, denota-se a incipiente compreensão de que as crianças são informantes capazes de participar e expor sua visão singular, considerando-se significativa diante do contexto escolar. Entretanto, para conhecer a criança desta maneira, seria necessário revolucionar a concepção vigente de infância, que indica "uma condição social subalterna, que nos remete à acepção de grande e pequeno e que se refere às hierarquias do poder mais do que idade". (Pancera, 1994, p.100).

Das marcas encontradas pelas produções, evidencia-se uma excessiva fragmentação temática que parece recortar o ensino fundamental em fatias investigativas que podem encobrir a verdadeira natureza do objeto de estudo em questão - a escola pública de ensino fundamental, descontextualizando-o. Desta averiguação a autora sublinha que há uma grande lacuna representada pelos poucos estudos que versam sobre os temas "aluno" e "fracasso escolar" exatamente os que estão diretamente relacionados com o nó górdio da educação brasileira.

As averiguações têm seu reflexo na pesquisa destacada pela autora, onde também é constatada a fragmentação da escola como objeto de estudo e ausência da criança na produção acadêmica. Destaca-se, ainda, a lacuna nos estudos mais detalhados que aprofundem a compreensão sobre a escola contemporânea.

Nesta direção que a autora se propõe a tal investigação: abordar como uma parcela da produção acadêmica - neste caso uma amostra de dissertações da área da educação - concebe os conceitos de infância, criança e escola e como explica as relações entre eles. Pressupõe que o estudo de tais conceitos de tais categorias indicará um modo de observar a relação infância e escola, fundamentando o conhecimento produzido na área. 
Debruçando-se sobre um campo de estudos em construção, com destaca Quinteiro (2002), em seu artigo Infância e Educação no Brasil: um campo de estudos em construção:

nas duas últimas décadas [ a produção sobre o tema infância no capo da educação no Brasil parece ter ampliado o seu campo de intervenções e, também, adquirido algum estatuto teórico metodológico. Os estudos sobre a infância como uma questão pública e não apenas privada começam a pipocar na produção acadêmica brasileira. Constata-se em produção caracterizada por diversos temas, pautados por estudos empíricos e ausência de debates teóricos, voltados a problemas relativos à história social da infância, às péssimas condições de vida e existência das crianças e de suas famílias, ao profundo desrespeito do Estado à criança como sujeitos de direitos e, sobretudo, aos diversos aspectos e especificidades que envolvem a educação e a proteção da criança de zero a seis anos de idade. (Quinteiro, 2002, p.20).

Confirmando a importância de pesquisas nesta perspectiva, cabe ressaltar a constatação de dois importantes estudos que realizaram um rastreamento das discussões sobre infância e educação nas últimas décadas, Kramer (1996) e Quinteiro (2001). A primeira autora evidencia na "necessidade de que seja realizado amplo e consistente estado da arte das pesquisas sobre a infância no Brasil, de modo a mapear a área, traçar um panorama das principais tendências teórico - metodológicas de investigação, discutir resultados e apontar tanto os avanços e conquistas quanto as (muitas) lacunas ainda existentes" (Kramer, 1996, p.27). Quinteiro acrescenta que "mais raras ainda, são as pesquisas que buscam articular a relação infância e escola, e, mais especificamente, que colocam o foco de suas análises na criança que está no aluno" (Quinteiro, 2001, p.18).

Ao identificar e delinear os conceitos de criança, infância e escola indicam-se o fundamento a partir do qual está sendo traçadas a relação infância e escola, revelando limites e possibilidades no modo de pensar a educação escolar da criança. Após esta contextualização, justifica-se a importância deste trabalho: examinar os produtos da atividade científica, trazendo uma contribuição ao mapeamento do campo Educação e Infância.

\section{Resumo.}

A pesquisa priorizou destacar as categorias infância, criança e escola, tendo em vista compreender como os pesquisadores trabalham esses conceitos, bem como o tipo de relação estabelecida entre as categorias infância e escola. A preocupação deste estudo foi traçar um panorama da produção acadêmica brasileira, identificando marcos que auxiliassem na compreensão das respectivas categorias. 
O foco da investigação centrou-se nas dissertações produzidas no período de 1994 a 2003, pois neste período as três categorias são objetos de preocupação dos autores e os textos analisados apresentavam explicitamente os referenciais teórico - metodológicos utilizados.

No primeiro capítulo a autora desdobra a relação infância escola sinalizando aspectos gerais da herança moderna para esta relação, tendo em vista realizar um exercício inicial da compreensão deste quadro até chegar à realidade da escola contemporânea. Destaca que a compreensão no século XIX sobre as crianças que pertenciam a esse grupo de idade era o reconhecimento de estatuto de "idade da razão" sendo "compreendido como ideal para a inserção na escola". Com a descrição de um breve panorama da pedagogia da Escola Nova, pode-se perceber que o projeto inovador brasileiro visava uma escola funcional em bases liberais, cuja compreensão da natureza infantil solicita menos a livre ação da criança e mais sua adaptação aos preceitos e regulações da vida em sociedade.

No entanto, se no início do século XX a relação infância e escola pode ser delineada pelo enfoque das capacidades individuais e na aposta de uma educação para a formação da burguesia; no final do século XX, esta relação não pode desconsiderar as condições socais em que as crianças estão sendo inseridas, assim como das características da instituição escolar que atende as massas, em um contexto de mundialização do capital e aumento das desigualdades.

O segundo capítulo a autora expõe o panorama teórico metodológico, buscando compreender neste capítulo a trajetória realizada para a elaboração do objeto de estudo. Primeiramente, explicita a visão aplicada sobre cada uma das categorias de pesquisa, pois estas revelam um modo específico de analisar o objeto em questão. Em seguida, explana os materiais envolvidos no processo de investigação, agrupando-os tematicamente, tendo em vista mapear a trajetória das categorias na produção acadêmica. Por último, destaca a amostra focalizada e justifica sua relevância.

O capítulo três tem como objetivo apresentar a amostra sobre qual a autora se deteve e os critérios estabelecidos para a construção da mesma. Descreve-se no mesmo a análise temática realizada sobre as categorias por meio do procedimento Análise do Conteúdo - explicitando as definições encontradas na amostra investigada sobre a categoria criança, e em seguida, sobre a categoria infância. Por meio desta descrição, pretendeu levantar elementos para compreender como as investigações da amostra focalizam a criança, aluno / aluna do ensino fundamental.

A autora no final do capítulo três problematiza a escola e defende nas palavras de Snyders o projeto indispensável para a escola contemporânea: transformá-la em um lugar privilegiado das alegrias da infância. Concluindo que é possível perceber o princípio diferenciado de pensar tais categorias, esperando que indiquem um futuro promissor para se alcançar a utopia proposta por Snyders para pensar a relação infância e escola: 
Cabe à escola encontrar um ponto de equilíbrio entre a criança como futuro adulto e a criança como atualmente criança. Uma criança que desejo que seja feliz em suas qualidades de jovem, no seu presente jovem, a começar pelo presente escolar. [...]

Eu gostaria de uma escola onde a criança não tivesse que saltar as alegrias da infância apressando-se em fatos e pensamentos, rumo à realidade adulta, mas onde pudesse apreciar sua especificidade os diferences momentos de suas idades (Snyders, 1993, p.29).

\section{Considerações Finais.}

Inicio as considerações trazendo a tona nas palavras de Azanha talvez síntese da análise desta dissertação:

De nada adiantaria simplesmente postular a fecundidade do estudo da vida cotidiana para o conhecimento do homem sem indicar como é possível obter esse conhecimento a partir da cotidianidade. Para isso é indispensável a formulação de teorias que indiquem seletivamente o que e como descrever e analisar aquilo que, sem elas, seria causo factual. (Azanha, 1992, p.66)

Essa compreensão foi o ponto essencial para que se desfaça de uma vez a ilusão de que basta admitir a importância da cotidianidade e então buscar a metodologia adequada para seu estudo, na esperança que desta forma chegaríamos a resultados interessantes. Para tanto, vale ressaltar que a importância do método adotado nos permite a apropriação do caráter totalizante ${ }^{1}$ do conhecimento. Entendendo que este seja o caminho para compreender o complexo essência/aparência, no qual, demanda recursos de um realismo crítico, científico que concebe o mundo como uma totalidade estruturada, diferenciada e em mudança e, por conseguinte, não pode, de forma alguma, ser reduzido aos limites do realismo empírico.

Dessa forma, embora a autora não tenha alcançado uma análise mais profunda, considerando o tempo de realização do mestrado, teve a preocupação de traçar um panorama da produção brasileira

\footnotetext{
1 Princípio metodológico de investigação dialética da realidade social é o ponto de vista da totalidade concreta, que antes de tudo significa que cada fenômeno pode ser compreendido como momento do todo. KOSIK, 1976. P. 49.
} 
bastante consistente, identificando marcos que utilizassem na compreensão das categorias criança, infância e escola. Acentuo a colocação da autora quando a realização da análise da produção acadêmica contribuiu para refletir os modos que se têm elaborado o conhecimento na área da educação.

Quanto ao procedimento utilizado, a Análise de Conteúdo, cabe alertar que a principal legitimidade está em possibilitar a desmontagem e caracterização dos textos em apreciação, que sucessivas leituras lineares dificilmente permitiram. O material reunido pela autora não foi utilizado em sua integralidade $e$ merece ser foco de outros olhares. Todavia, destaca-se que as conexões estabelecidas entre as categorias é o que produzem o fundamento para as elaborações/análises.

Ressalto ainda a importância da análise da autora discutida no segundo e terceiro capítulo podendo constatar um crescente interesse pelo tema infância, adensando-se na década de 1990 e nos iniciais anos 2000. A contribuição dos diferentes campos de estudo - especialmente história e sociologia - tem possibilitado ampliar a reflexão sobre a condição social da criança na realidade brasileira. Apesar das localizadas incursões que buscam estabelecer relação entre infância - escola podem-se observar as tensões sobre a socialização da criança na escola contemporânea. Por último, não menos significativo, a abordagem de um novo campo de estudos: a Sociologia da Infância em âmbito mundial e nacional.

Em suma, diante do exposto percebemos que os estudos em relação à infância estão ainda engatinhando, diante da prematuriedade e aceitação do tema. Já se admite, no entanto, que há certo deslocamento do enfoque psicológico para o sociológico na categoria infância. Levando-nos a indagar: os estudos sobre a infância estariam caminhando para além de admitir a presença da criança, mais, sobretudo para o conhecimento da condição social da criança?

\section{Referencial Bibliográfico.}

AZANHA, José Mário Pires. Uma idéia de pesquisa educacional. São Paulo: Editora da Universidade de São Paulo, 1992.

BATISTA, Ezir Mafra. Criança, Infância e Escola: Uma análise da produção discente no Brasil (1994 a 2004). Dissertação (Educação). Florianópolis: Universidade federal de Santa Catarina, 2006.

CANÁRIO, R. Os estudos sobre a escola: problemas e perspectivas. In: BARROSO, J. (org). 0 estudo da escola. Porto: Porto, 1996. p. 121-147.

GATTI, Bernadete A. A construção da Pesquisa em Educação no Brasil. Brasília: Plano Editora, 2002. 
KOSIK, Karel. Dialética do Concreto. 7 cd. Rio de Janeiro: Paz e Terra, 1976.

KRAMER, Sonia. Pesquisando infância e educação: um encontro com Walter Benjamim. In: KRAMER, Sonia; LEITE Maria Isabel. (orgs.). Infância: fios e desafios da pesquisa. Campinas, SP: Papirus, 1996.

PANCERA, Cano. Semânticas de infância. Revista Perspectiva, Florianópolis, n.22, p.97-I04, ago./dez. 1994.

QU1NTEIRO, Jucirema. Infância e educação no Brasil: um campo de estudos em construção. In: XXIV Reunião da Anped. Caxambu, MG: 2001. Anped - 25 anos. Caxambu, MG: 2001. CD ROM.

QUINTEIRO, Jucirema. Infância e educação no Brasil: um campo de estudos em construção. 2002. In: FARIA, Ana Lúcia Goulart de; DEMART1NI, Zeila de Brito Fabri; PRADO, Patrícia Dias. Por uma cultura da infância. Campinas, SP: Autores Associados, 2002.

SNYDERS, Georges. Alunos felizes: reflexão sobre a alegria na escola a partir de textos literários. Rio de Janeiro: Paz e Terra, 1993. 